\title{
The significant factors causing delay of building construction projects in Malaysia.
}

\begin{abstract}
Purpose - The paper seeks to identify the major factors causing delay in building construction projects in Malaysia. Design/methodology/approach - A questionnaire survey was used to carry out the study. The questionnaire consisted of 31 factors which were grouped into four major categories by responsibility - contractor factors, owner factors, consultant factors and external factors. The level of importance of the categories was measured and the relative importance of weights was ranked. Findings - The study finds that financial problems are the main factor and coordination problems are the second most important factor causing delay in construction projects in Malaysia. The results were analyzed to rank the causes of delay and further classify the types of delay. Research limitations/implications - The scope of this study is limited to building projects in the Klang Valley area, where major Malaysian cities such as Kuala Lumpur, Putrajaya, Petaling Jaya, Shah Alam and Seremban are located. The data for this study was gathered through a detailed questionnaire survey. Originality/value - Based on the analysis of the ranking and intensity of causes of delay, this paper suggests possible improvements that could be made in order to reduce delays in the construction industry.
\end{abstract}

Keyword: Construction industry; Project management; Malaysia. 